\title{
SYNTHESIS AND CHARACTERIZATIONOF ORGANIC FUNCTIONALIZED MESOPOROUS SILICA AND EVALUATE THEIR ADSORPTIVE BEHAVIOR FOR REMOVAL OF METHYLENE BLUE FROM AQUEOUS SOLUTION
}

\author{
${ }^{1}$ Sameer H. Kareem, ${ }^{1}$ Inaam H. Ali and ${ }^{2}$ M.G. Jalhoom \\ ${ }^{1}$ Department of Chemistry, College of Science for Women, Baghdad University, Iraq \\ ${ }^{2}$ Ibn Sina State Company, Ministry of Industry and Minerals, Iraq
}

Received 2013-12-12; Received 2014-02-15; Accepted 2014-02-28

\begin{abstract}
Three Mesoporous Silica (MPS) with different functional groups were prepared by one-step synthesis based on the simultaneous hydrolysis and condensation of tetraethoxy silane with organo-silane in the presence of template surfactant Polydimethylsiloxane-Polyethyleneoxide (PDMS-PEO). The prepared materials were characterized by Fourier Transform Infrared Spectroscopy (FTIR), Thermogravimetric Analysis (TGA) and nitrogen adsorption-desorption experiments. The results indicate that the preparation of methyl and phenyl functionalized silica were successful. The adsorption behavior of methylene blue from aqueous systems onto these mesoporous silica has been studied. Batch experiments were carried out to measure the adsorption as a function of contact time, initial concentration $\left(2.5-20 \mathrm{mg} \mathrm{L}^{-1}\right)$ and temperature $(288,298,308$ and $318 \mathrm{~K})$. The equilibrium of the process was achieved within (30-60) min. The adsorption of methylene blue on the mesoporous silica increases with increasing temperature which indicating an endothermic process. Adsorption isotherms were fitted with the Langmuir, Freundlich models. The kinetic data were analyzed using pseudofirst- order and pseudo-second-order models and intraparticle diffusion. The adsorption kinetics of methylene blue on mesoporous silica matched well with pseudo-second order kinetic model.
\end{abstract}

Keywords: Functionalized Mesoporous Silica, Silicone Surfactants, Methylene Blue, Adsorptive Properties

\section{INTRODUCTION}

Mesoporous materials are porous particles where the pore size according to the IUPAC classification is between 2 to $50 \mathrm{~nm}$ (Sing et al., 1985). These materials have attracted a great deal of interest and wide range of applications in catalyst (Branton et al., 1993), adsorbents (Desplantier-Giscard et al., 2001) and sensors (Meynen et al., 2009) due to their structural properties which have high surface area and large pore volumes. Mesoporous silica are silicates obtained by hydrothermal synthesis and a liquid templating mechanism (Monnier et al., 1993). Template synthesis using silicone surfactant has been proven to be an efficient approach to tune pore size of mesoporous silica.
Silicones modified with hydrophilic Polyethyleneoxide (PEO) have a strong tendency to orient at the interface between two incompatible phases caused by their surface active properties and provide maximum benefit at low concentrations. Graft copolymer (PDMS-PEO) composed of Polydimethylsiloxane (PDMS) backbone and branched PEO has been most extensively studied. Despite wide and extensive industrial usage, very little information is available in the literature on the fundamental surfactant properties of PDMS-PEO in the synthesis of mesoporous materials (Chung et al., 2006; Liu, 2009). To our knowledge this is the first work in which the surfactant (PDMS-PEO) was used as a template in the synthesis of organofunctionalized mesoporous silica.

Corresponding Author: Sameer, H. Kareem, Department of Chemistry, College of Science for Women, Baghdad University, Iraq 
Functionalization of the surface of these mesoporous materials with organic or inorganic functional groups leads to new physical and chemical properties. These modified materials can be used in adsorption due to specific porous structure and the excellent textual properties which allow easier diffusion of large molecules into the active sites (Corma et al., 2004; Norhasyimi et al., 2010).

Therefore, some dyes can be used to study their adsorptive properties. Methylene Blue (MB) (3,7-bis (dimethylamino)-phenothiazin-5-ium chloride) is a heterocyclic aromatic chemical compound with the molecular formula $\left(\mathrm{C}_{16} \mathrm{H}_{18} \mathrm{~N}_{3} \mathrm{SCl}\right)$. It has many uses in a range of different fields, such as biology and chemistry. MB is employed in some medical uses in large quantities, it can also be widely used in coloring paper, dyeing cottons, wools, coating paper of stocks, (Soni et al., 2012; Anbia and Hariri, 2010). Although $\mathrm{MB}$ is not strongly hazardous, it can cause some harmful effects. Wang and Li (2006) investigated the dynamic adsorption of MB on mesoporous silica with different structures. They found that dye adsorption presents reversible or irreversible behavior in dye solution depending on the structure of mesoporous materials. The research showed that the ordered mesoporous silica adsorbents prepared by grafting amino- and carboxylic-containing functional groups onto MCM-41 maintained selectivity of dyes. The amino-containing adsorbent has a large adsorption capacity and a strong affinity for the Acid blue 25 .

In the present work, organo-functionalized mesoporous silica were prepared using PDMS-PEO as a template and FT-IR, TGA and N2 physical adsorption techniques were used to characterize these materials. They were used to study the adsorption of MB dye from aqueous solution and the kinetics and thermodynamics models were used to estimate the rate of adsorption, adsorption capacity and the mechanism of adsorption.

\section{MATERIALS AND METHODS}

\subsection{Materials}

Tetraethoxysilane (TEOS) was used as a silica source purchased from Sigma-Aldrich and the surfactant (polydimethylsiloxane-polyethyleneoxide PDMS-PEO) as a copolymer was purchased from bayer company. Methyltrichlorosilane (MTES) and Phenyltrichlorosilane (PTES) were purchased from Fluka AG. Hydrochloric acid and absolute ethanol were purchased from BDH.

\subsection{Instruments}

There are many techniques which have been used in the characterization of the prepared silica, these are as follows:

- The IR spectra of silica samples were recorded over the range of $4000-400 \mathrm{~cm}^{-1}$ by means of Fourier Transform Infrared Spectroscopy (FTIR), using FTIR spectrometer SHIMADZU

- Thermogravimetric Analysis (TGA) was perfomed using Perkin-Elmer TGA7 instrument, from $30.00^{\circ} \mathrm{C}$ to $900.00^{\circ} \mathrm{C}$ at heating rate $20.00^{\circ} \mathrm{C} / \mathrm{min}$ using helium as inert gas

- The texture analysis of the surfaces areas were determined from $\mathrm{N}_{2}$ adsorption-desorption isotherm at $77 \mathrm{~K}$ with Micrometrics ASAP 2020 V3.04G analyzer (micromeritics, Inc., USA)

\subsection{Synthesis}

The preparation of inorganic and organic functionalized silica has been performed following procedure: $1 \mathrm{~g}$ of (PDMS-PEO) was dissolved in $25 \mathrm{~mL}$ of deionized water under shaking then $15 \mathrm{~mL}$ of $36 \%$ $\mathrm{HCl}$ were added to this solution. In another beaker $5 \mathrm{~mL}$ of TEOS was mixed with $5 \mathrm{~mL}$ of METS or $6 \mathrm{~mL}$ of PTES, this mixture were added drop wise to the mixture of surfactant and acid. The obtained white precipitate was formed spontaneously and then it was recovered by filtration, washed and dried at $373 \mathrm{~K}$. The surfactant was removed by stirring $1 \mathrm{~g}$ of the dried sample with a solution of $5 \mathrm{~mL}$ of $\mathrm{HCl}(36 \%)$ in a $150 \mathrm{~mL}$ of ethanol at $60^{\circ} \mathrm{C}$ for $1 \mathrm{~h}$. The quantitative removal of the surfactant required in general two consecutive extractions.

\subsection{Adsorption Study}

Adsorption experiments were carried out in $250 \mathrm{~mL}$ conical flasks immersed in a thermostatic shaker bath. 50 $\mathrm{mg}$ of mesoporous silica samples was mixed with $50 \mathrm{~mL}$ of the aqueous solutions of various initial concentrations (2.5-20 mg L ${ }^{-1}$ ) of methylene blue (Fluka). The flasks with their contents were shaken for different adsorption times at the temperatures of 288, 298, 308 and $318 \mathrm{~K}$. At the end of adsorption interval; the supernatant was centrifuged for $20 \mathrm{~min}$. The concentration of MB in the supernatant solution before and after the adsorption was determined with a $1.0 \mathrm{~cm}$ light path quartz cells using UV-Visible Spectrophotometer (SHIMADZU) at maximum wavelength $\left(\lambda_{\max }\right)$ of $664 \mathrm{~nm}$. The amount of 
adsorbed dye at equilibrium $\mathrm{q}_{\mathrm{e}}\left(\mathrm{mg} \mathrm{g}^{-1}\right)$ was calculated from the following Equation (1):

$\mathrm{q}_{\mathrm{e}}=\frac{(\mathrm{Co}-\mathrm{Ce}) \mathrm{V}}{\mathrm{W}}$

where, $\mathrm{C}_{\mathrm{o}}$ and $\mathrm{C}_{\mathrm{e}}\left(\mathrm{mg} \mathrm{\textrm {L } ^ { - 1 }}\right)$ are the liquid phase concentrations of dye at initial and equilibrium stages respectively, $\mathrm{V}(\mathrm{L})$ is the volume of the solution and $\mathrm{W}$ (g) is the mass of adsorbent used.

\section{RESULTS}

\subsection{Characterization}

\subsubsection{FTIR}

The silica were characterized by FTIR spectroscopy between 4000 and $400 \mathrm{~cm}^{-1}$ and represented in (Fig. 1). For unfunctionalized MPS (Fig. 1a) The absorption bands observed at around 3446 and $956 \mathrm{~cm}^{-1}$ indicate the presence of water and $-\mathrm{OH}$ groups. The intensities of these bands are decreased in the samples of silica functionalized with methyl and phenyl groups which indicate the hydrophobic behavior of the functionalized silica. Also, the vibration of the $\mathrm{Si}-\mathrm{O}-\mathrm{Si}$ bond is represented by the absorption band at $1072 \mathrm{~cm}^{-1}$ which are strong in all samples (Rami and Houssam, 2009).
The main features of the spectra of silica functionalized by methyl (Fig. 1b) group were the characteristic band for aliphatic C-H stretching vibration of methyl group at around $3000-2800 \mathrm{~cm}^{-1}$ and the strong sharp band at $1276 \mathrm{~cm}^{-1}$, characteristic of the symmetric bending mode of the methyl group in methylsilanes (Yu et al., 2010). These results provide evidence that the preparation of methyl functionalized silica was successful.

The absorption peaks of phenyl group are observed at which associated with the stretching vibration of ring $\mathrm{C}-\mathrm{H}$ and out-of-plane bending of $\mathrm{C}-\mathrm{H}$ bonds are clearly identifiable at 1431, 698 and $740 \mathrm{~cm}^{-1}$ respectively (Fig. 1c). Also, the appearance of an additional peak at $3074 \mathrm{~cm}^{-1}$ indicates the presence of aromatic C-H bonds (Ryouya et al., 2012). This suggesting that the phenyl groups have been incoporated into the silicate network.

\subsection{TGA}

Thermogravimetric analysis of unfunctionalized and functionalized MPS are shown in Fig. 2 indicate that initial weight loss betweem $100-200^{\circ} \mathrm{C}$ resulted from desorption of water molecules and residual ethanol used in the solvent extraction process. This was followed by weight loss up to $450^{\circ} \mathrm{C}$ which corresponds to the residual surfactant decomposition and silanol condensation (Li and Zhai, 2011).

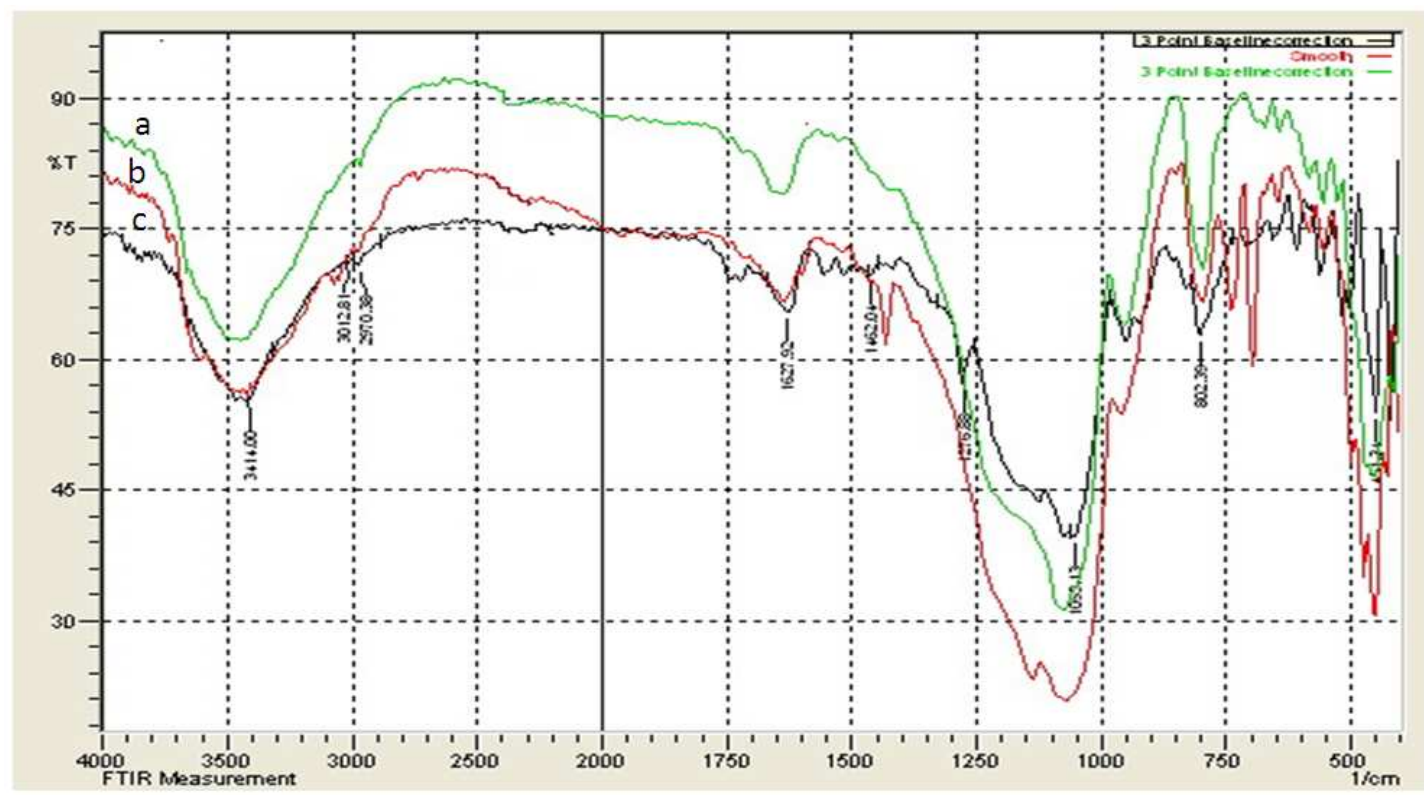

Fig. 1. FT-IR spectra of : (a) unfunctionalized MPS (b) phenylfunctionalizedmps (c) Methylfunctionalized MPS 


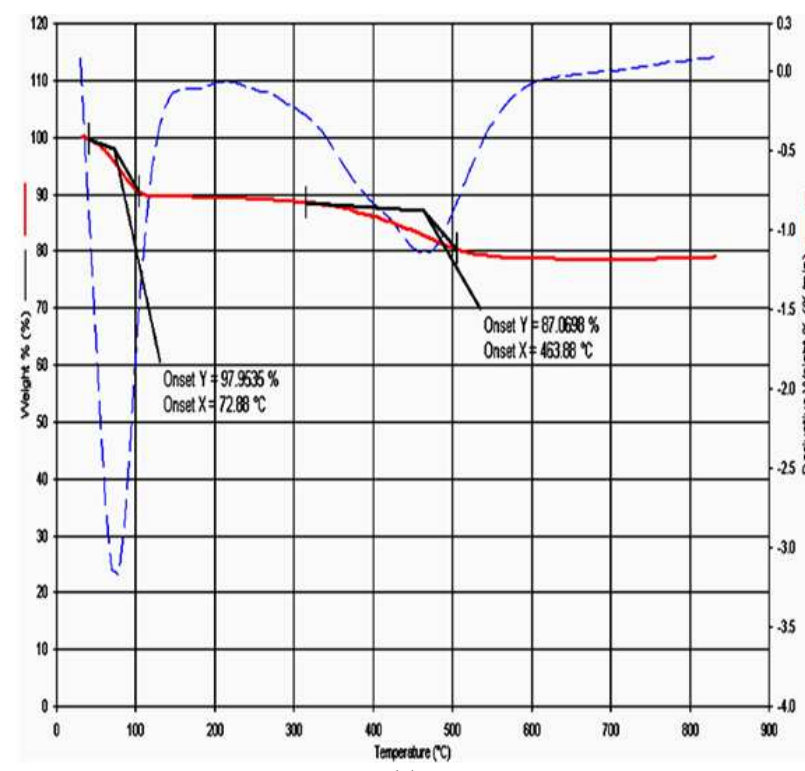

(a)

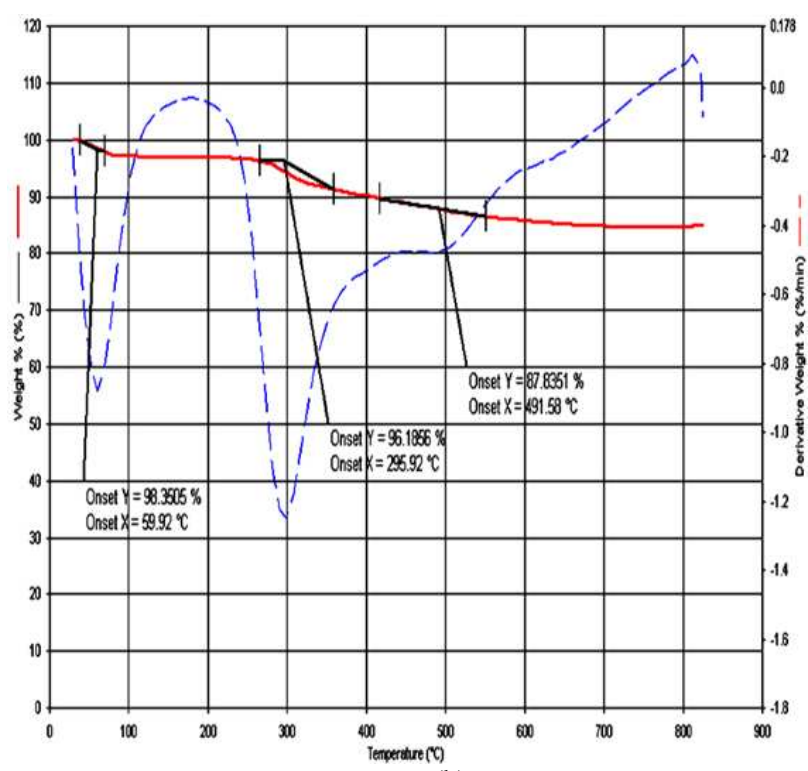

(b)

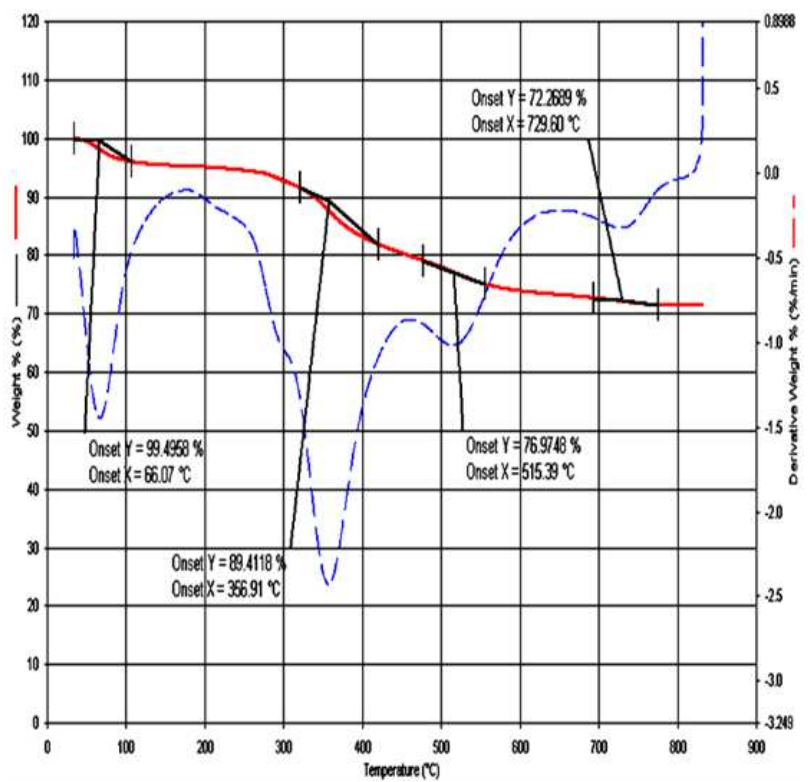

(c)

Fig. 2. TGA and DTA curves of (a) unfunctionalized MPS (b) Methyl Functionalized MPS(c) phenyl functionalized MPS

For methyl functionalized MPS, the mass loss observed in the temperature range $270-360^{\circ} \mathrm{C}$ which was attributed to oxidation of the $\mathrm{Si}-\mathrm{CH}_{3}$ group to $\mathrm{Si}-\mathrm{OH}$. Another exothermic peak and a weight loss in the range $420-560^{\circ} \mathrm{C}$ were corresponding to dissociation of the surface organic groups. For phenyl functionalized silica, the decomposition of phenyl group was observed in the temperature range $450-730^{\circ} \mathrm{C}$.

\section{3. $\mathbf{N}_{2}$ Adsorption-Desorption Isotherms}

The adsorption isotherms for the three types of silica used in the present work can be considered type IV (Fig. 3) according to the common classification of adsorption isotherms. The hysteresis loops observed are typical for mesoporous materials and resemble different types of loops according to the IUPAC classification (Sing et al., 1985; Rouquerol et al., 1994). 


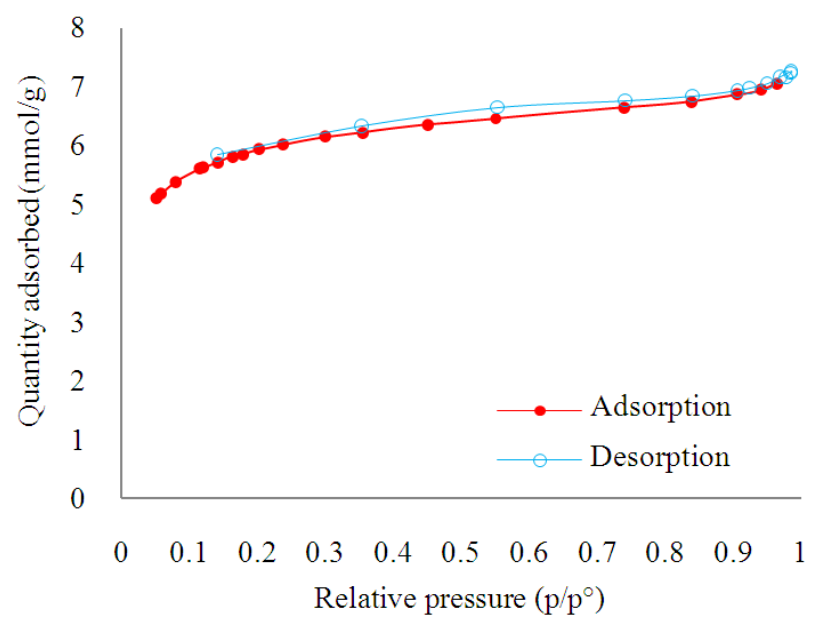

(a)

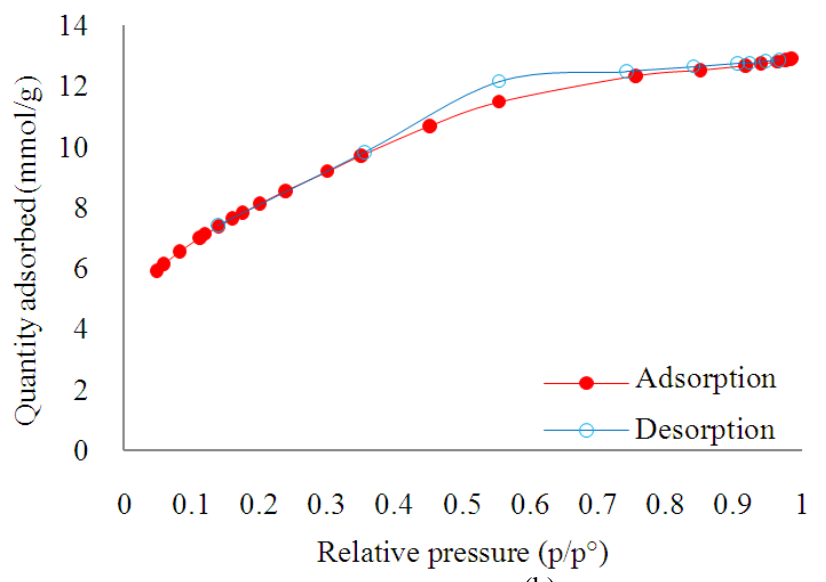

(b)

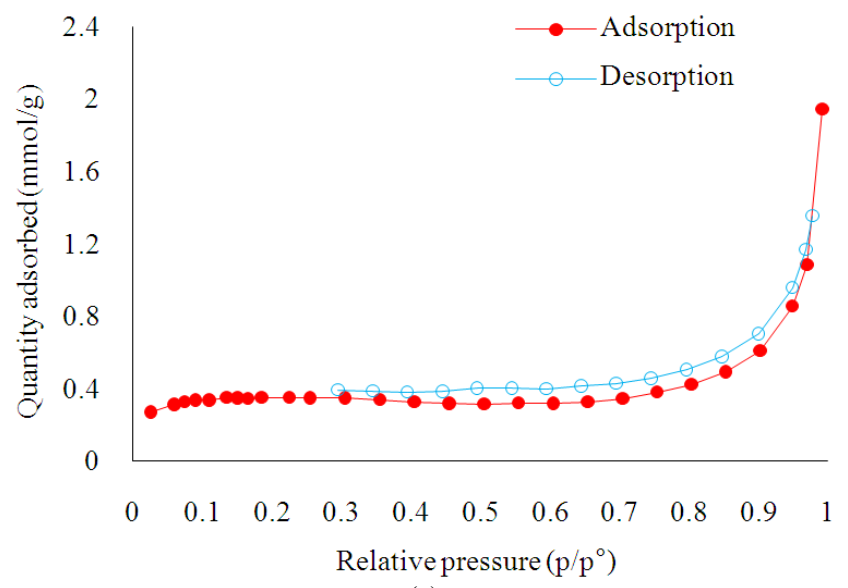

(c)

Fig. 3. $\mathrm{N}_{2}$ Adsorption-desorption isotherms of (a) unfunctionalized silica (b) methyl functionalized silica (c) phenyl functionalized silica

As can be seen from (Fig. 3a), the hysteresis loop of the isotherm of unfunctionalized silica is the type $\mathrm{H} 4$. This is typical of aggregated particles that form narrow slits pores. The hysteresis loops of the isotherm of methyl and phenyl functionalized silica are the type $\mathrm{H} 2$ and $\mathrm{H} 3$ respectively Fig. $3 \mathbf{b}$ and $\mathbf{c}$, which often referred to as ink-bottle pores and slit like pores respectively.

Specific surface areas were calculated following the BET procedure (Brunauer et al., 1938). Pore size distribution was obtained by using the $\mathrm{BJH}$ pore analysis (Barrett et al., 1951) applied to the adsorption branch of the nitrogen adsorption/desorption isotherm which relies on the Kelvin equation (Johanson, 2010) to relate the width of the pores to the condensation pressure. The results of pore size distribution confirm the presence of mesoporosity in the samples prepared and show a narrow pore size distribution (from 1 to $5 \mathrm{~nm}$ ) for methyl functionalized MPS, while unfunctionalized and phenyl functionalized MPS show wide range distribution (from 1 to $100 \mathrm{~nm}$ ).

The structural properties, specific surface area and pore volume, of the surface of the studied silica estimated from nitrogen adsorption-desorption are shown in Table 1.

\subsection{Adsorption Behavior}

\subsubsection{Effect of Adsorbent Dose}

Effect of adsorbent dose on removal of MB was monitored by varying adsorbent dose from (25-125) $\mathrm{mg} / 50 \mathrm{~mL}$ of $\mathrm{MB}$ solution. The adsorption of dye 
increased with the adsorbent dosage and reached on equilibrium value after of adsorbent (Fig. 4) as one was accepted, the percentage of dye removal increased with increasing amount of MPS, however the ratio of dye adsorbed to MPS (mg/g) decreased with increasing amount of adsorbent. The maximum dye removal was achieved within $50 \mathrm{~min}$ for unfunctionalized MPS, $30 \quad \mathrm{~min}$ for methylfunctionalized MPS and $60 \mathrm{~min}$ for phenylfunctionalized MPS.

\subsection{Adsorption Isotherm}

The adsorption isotherms of MB on the three MPS at $298 \mathrm{~K}$ are shown in (Fig. 5), equilibrium uptake increased with the increasing of equilibrium $\mathrm{MB}$ concentrations at the range of experimental concentration.

The isotherm usually describes the adsorption system with some important information from which we can develop an equation representing the results and we can use the equation for certain purposes. In order to investigate the adsorption isotherm, two equilibrium isotherms were analyzed: The Langmuir and Freundlich. The Langmuir adsorption isotherm is perhaps the best known of all isotherms describing adsorption (Langmuir, 1918) Equation (2):

$$
\frac{\mathrm{C}_{\mathrm{e}}}{\mathrm{q}_{\mathrm{e}}}=\frac{1}{\mathrm{~K}_{\mathrm{L}} \cdot \mathrm{Q}^{\circ}}+\frac{\mathrm{C}_{\mathrm{e}}}{\mathrm{Q}^{\circ}}
$$

Where:

$\mathrm{q}_{\mathrm{e}}=$ The equilibrium adsorption capacity $\left(\mathrm{mg} \mathrm{g}^{-1}\right)$

$\mathrm{C}_{\mathrm{e}}=$ The equilibrium liquid phase concentration $\left(\mathrm{mg} \mathrm{L}^{-1}\right)$

$\mathrm{Q}^{\circ}=$ The maximum adsorption capacity $\left(\mathrm{mg} \mathrm{g}^{-1}\right)$

$\mathrm{K}_{\mathrm{L}}=$ Adsorption equilibrium constant $\left(\mathrm{L} \mathrm{mg}^{-1}\right)$

The Freundlich isotherm is the earliest known relationship describing the adsorption isotherm (Freundlich, 1906). This fairly satisfactory empirical isotherm can be used in adsorption from diluted solutions. The ordinary adsorption isotherm is expressed by the following Equation (3):
$\operatorname{In} \mathrm{q}_{\mathrm{e}}=\operatorname{In} \mathrm{K}_{\mathrm{f}}+\frac{1}{\mathrm{n}} \operatorname{In} \mathrm{C}_{\mathrm{e}}$

$\mathrm{K}_{\mathrm{f}}=$ An indicator of adsorption capacity and

$\mathrm{n}=$ The heterogeneity factor and giving an indication of the favorability of adsorption

The parameters obtained from the two models are listed in Table 2.

\subsection{Adsorption Kinetics}

Several kinetic models can be used to express the mechanism of solute sorption onto a sorbent. In this study, pseudo-first-order and pseudo-second order kinetic models were tested. A linear form of pseudo-first order kinetic was described by Lagergren (1898) Equation (4):

$\log \left(\mathrm{q}_{\mathrm{e}}-\mathrm{q}_{\mathrm{t}}\right)=\log \mathrm{q}_{\mathrm{e}}-\left(\mathrm{k}_{1} / 2.303\right) \mathrm{t}$

where, $\mathrm{q}_{\mathrm{e}}$ and $\mathrm{qt}$ are the adsorption capacities at equilibrium and at time $\mathrm{t}$, respectively $\left(\mathrm{mg} \mathrm{g}^{-1}\right) ; \mathrm{k}_{1}$ is the rate constant of pseudo-first order adsorption $\left(\mathrm{L} \mathrm{min}^{-1}\right)$.

The pseudo-second-order equation of McKay can be represented in the following form (McKay and Ho, 1999) Equation (5):

$\frac{\mathrm{t}}{\mathrm{q}_{\mathrm{e}}}=\frac{1}{\mathrm{k}_{2} \mathrm{q}_{\mathrm{e}}^{2}}+\left(\frac{1}{\mathrm{q}_{\mathrm{e}}}\right) \mathrm{t}$

where, the pseudo-second-order constants $\mathrm{k}_{2}$ (g (mg $\min )^{-1}$ ) and the equilibrium adsorption capacity $\mathrm{q}_{\mathrm{e}}$ can be determined experimentally from the slope and intercept of the plot $t / q_{t}$ versus $t$. The intraparticle diffusion model is commonly used for identifying the steps involved during adsorption with the pseudosecond-order rate equation. It is described by external mass transfer (boundary-layer diffusion) and intraparticle diffusion (Weber and Morris, 1963). The diffusion model expressed as Equation (6):

$$
\mathrm{q}_{\mathrm{t}}=\mathrm{k}_{\mathrm{d}}^{1 / 2}+\mathrm{c}
$$

Table 1. Textural data of the synthesis materials

\begin{tabular}{llll}
\hline Materials & $\begin{array}{l}\text { BET specific } \\
\text { surf. area }\left(\mathrm{m}^{2} / \mathrm{g}\right)\end{array}$ & $\begin{array}{l}\text { Total pore } \\
\text { vol }\left(\mathrm{cm}^{3} / \mathrm{g}\right)\end{array}$ & $\begin{array}{l}\text { BJH av. Pore } \\
\text { width (nm) }\end{array}$ \\
\hline Un functionalized mesoporous silica & 424.3420 & 0.250500 & 2.3613 \\
Methyl functionalized mesoporous silica & 646.9624 & 0.446880 & 2.7629 \\
Phenyl functionalized mesoporous silica & 1.2792 & 0.002889 & 9.0338 \\
\hline
\end{tabular}


Sameer H. Kareem et al. / American Journal of Environmental Science 10 (1): 48-60, 2014

Table 2. Langmuir and freundlich parameters for adsorption on MPS

\begin{tabular}{|c|c|c|c|c|c|c|c|c|c|c|c|c|c|}
\hline \multicolumn{2}{|c|}{ Type of silica } & \multicolumn{3}{|c|}{ Unfunctionalized MPS } & \multicolumn{4}{|c|}{ Methyl functionalized MPS } & \multicolumn{5}{|c|}{ Phenyl functionalized MPS } \\
\hline Model & Temp. K & 288 & 298 & 308 & 318 & 288 & 298 & 308 & 318 & 288 & 298 & 308 & 318 \\
\hline Freundlich & $\mathrm{n}$ & 1.9340 & 2.6109 & 3.2670 & 4.166 & 2.080 & 3.154 & 3.484 & 4.695 & 2.353 & 2.028 & 2.506 & 2.487 \\
\hline \multirow[t]{2}{*}{ Parameters } & $\mathrm{K}_{\mathrm{f}}$ & 4.7090 & 6.8760 & 8.2413 & 9.311 & 5.675 & 7.906 & 8.790 & 10.092 & 2.306 & 2.208 & 4.139 & 4.425 \\
\hline & $\mathrm{R}^{2}$ & 92.3000 & 67.9000 & 78.7000 & 82.900 & 96.600 & 93.300 & 95.400 & 96.100 & 98.300 & 95.800 & 96.800 & 97.600 \\
\hline Langmuir & $\mathrm{Q}_{\mathrm{o}}$ & 14.2800 & 13.5100 & 13.5100 & 13.510 & 15.150 & 14.280 & 14.490 & 14.708 & 8.547 & 9.615 & 12.195 & 13.157 \\
\hline \multirow[t]{2}{*}{ Parameters } & $\mathrm{K}_{\mathrm{L}}$ & 0.5932 & 1.6080 & 3.0830 & 5.285 & 0.750 & 1.892 & 2.555 & 3.400 & 0.275 & 0.237 & 0.463 & 0.460 \\
\hline & $\mathrm{R}^{2}$ & 99.5000 & 99.7000 & 99.7000 & 99.600 & 99.800 & 99.100 & 99.100 & 99.100 & 96.200 & 99.400 & 95.700 & 96.100 \\
\hline
\end{tabular}

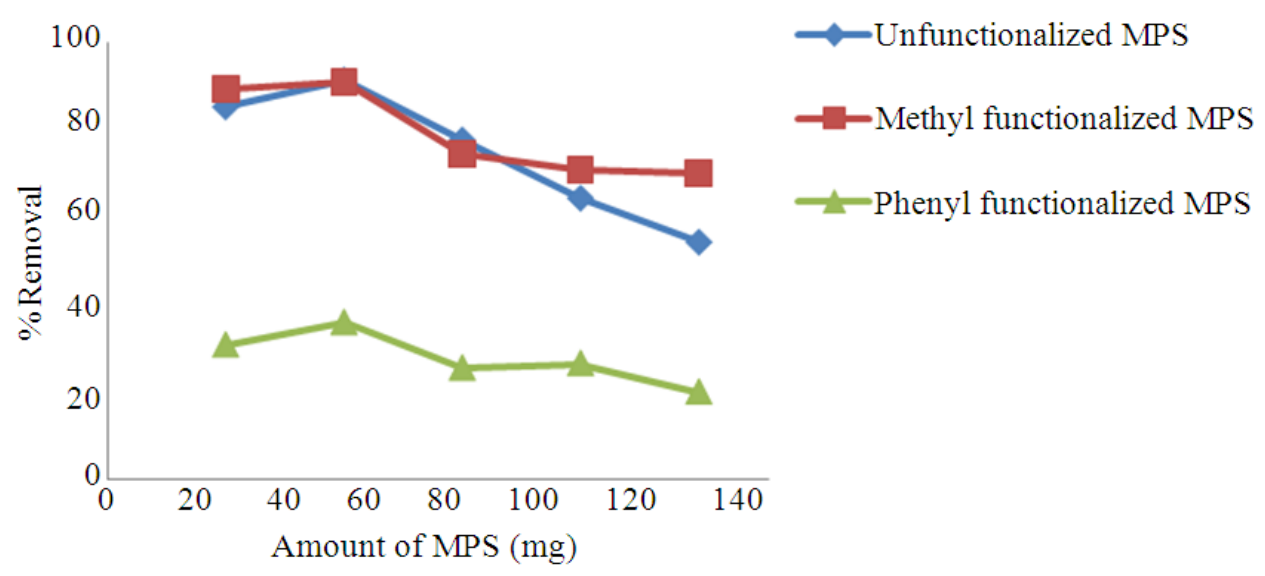

Fig. 4. Effect of adsorbent dose on removal of $\mathrm{MB}$ for concentration $10 \mathrm{mg} / \mathrm{L}^{-1}$

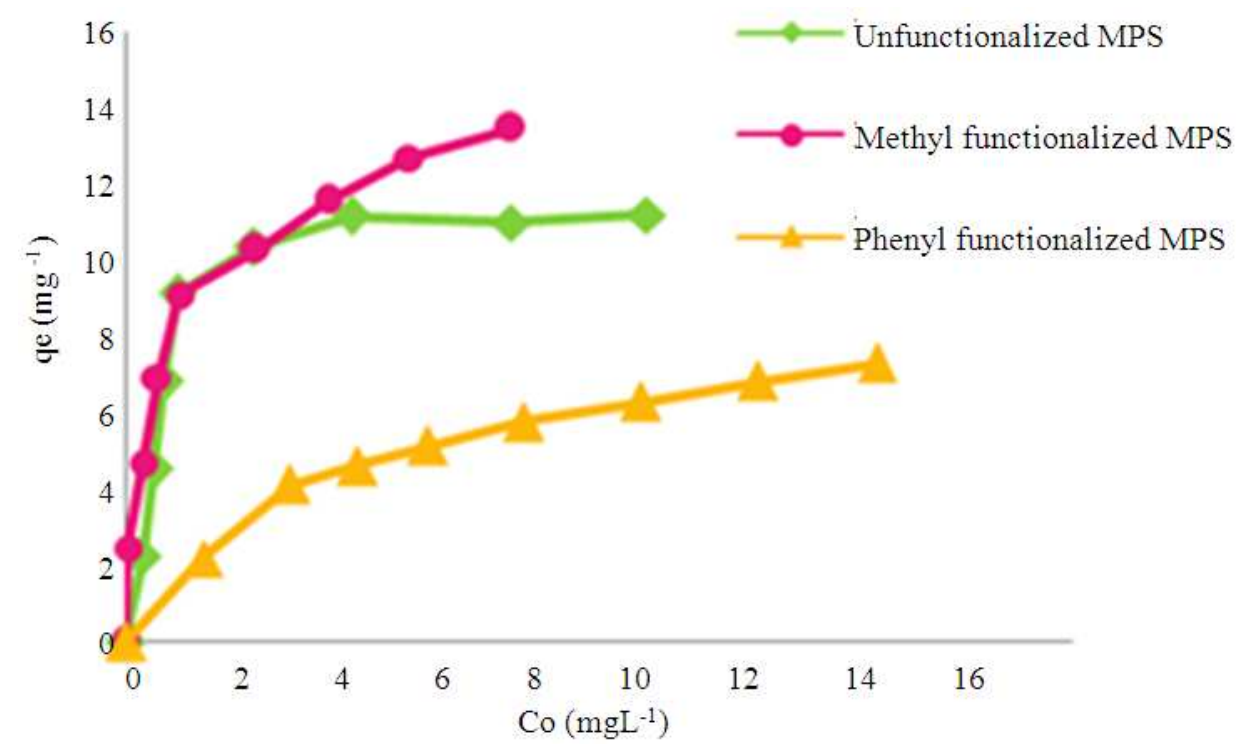

Fig. 5. Adsorption isotherms of MB on different MPS 


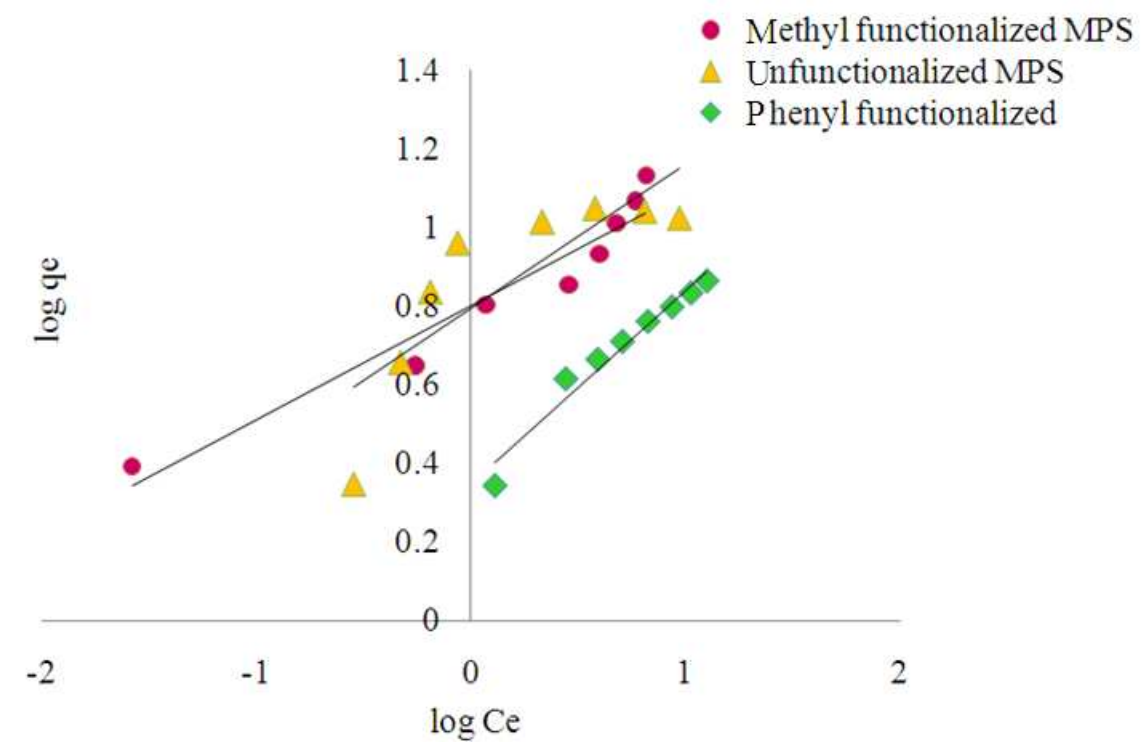

(a)

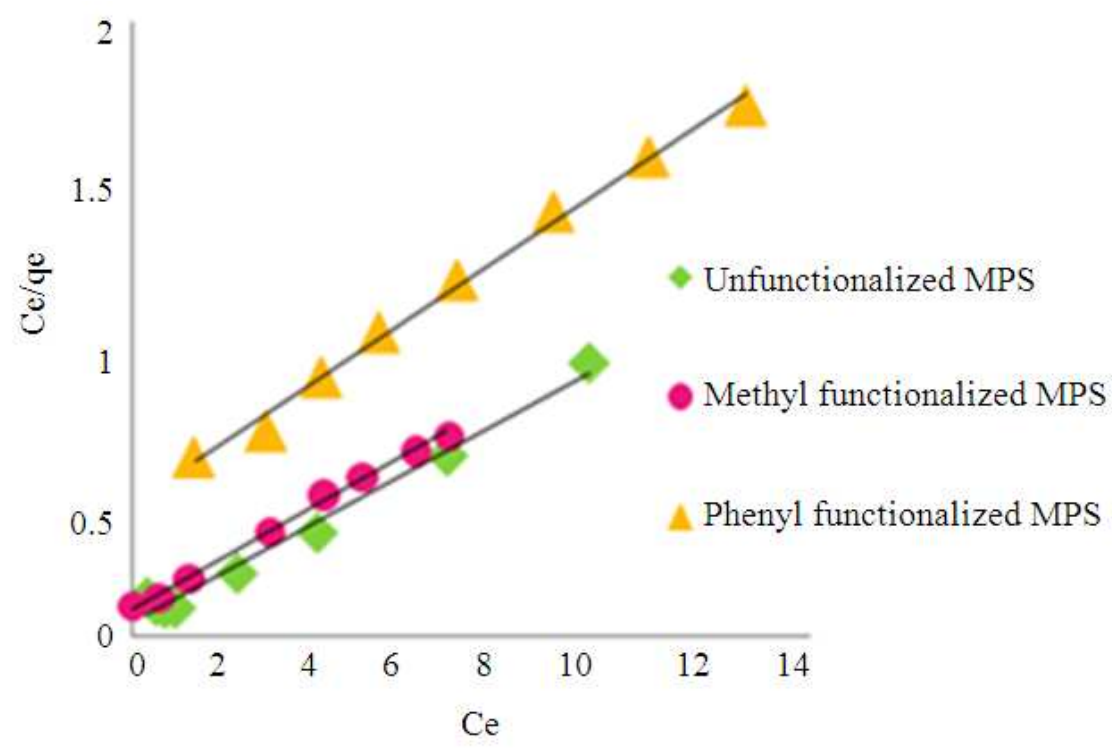

(b)

Fig. 6. (a)shows the linear plots of the langmuir and freundlich model (b)Adsorption isotherms of MB on MPS at 298K fitted by; (a) Frendulich isotherm (b) Langmuir isotherm

Where:

$\mathrm{k}_{\mathrm{d}}=$ The diffusion coefficient and

$\mathrm{c}=$ The intercept

The adsorption of methylene blue on MPS using the pseudo-first-order kinetics, pseudo-second-order kinetics and diffusion model is shown in Fig. 7 and the kinetics parameters obtained are listed in Table 3.

\subsection{Thermodynamics Analysis}

The free energy change $\left(\Delta \mathrm{G}^{\circ}\right)$, enthalpy change $\left(\Delta \mathrm{H}^{\circ}\right)$ and entropy change $\left(\Delta \mathrm{S}^{\circ}\right)$ were determined. The 
Langmuir isotherms were used to calculate thermodynamic parameters using the following equations (Onal, 2006; Karaca et al., 2008):

$$
\begin{aligned}
& \Delta \mathrm{G}^{\circ}=\operatorname{RT} \operatorname{In} \mathrm{K}_{\mathrm{L}} \\
& \text { In } \mathrm{K}_{\mathrm{L}}=\frac{\Delta \mathrm{S}^{\circ}}{\mathrm{R}}-\frac{\Delta \mathrm{H}^{\circ}}{\mathrm{RT}}
\end{aligned}
$$

The slope and intercept of the van't Hoff plot is equal to- $\Delta H / R$ and $\Delta$ So/R, respectively where $R$ is the universal gas constant $8.314 \mathrm{~J} /(\mathrm{mol} \mathrm{K}) ; \mathrm{T}$ is the absolute temperature (K).

Thermodynamic parameters obtained are summarized in Table 4.

\begin{tabular}{|c|c|c|c|c|c|c|c|c|c|c|c|c|c|}
\hline \multicolumn{3}{|c|}{ Type of silica } & \multicolumn{3}{|c|}{ Unfunctionalized MPS } & \multicolumn{4}{|c|}{ Methyl functionalized MPS } & \multicolumn{4}{|c|}{ Phenyl functionalized MPS } \\
\hline Model & Temp. K & 288 & 298 & 308 & 318 & 288 & 298 & 308 & 318 & 288 & 298 & 308 & 318 \\
\hline Pseudo & qe & 8.8300 & 16.6300 & 9.7050 & 9.5500 & 14.0600 & 12.0500 & 15.4100 & 10.2100 & 2.7800 & 4.0000 & 3.2500 & 3.5700 \\
\hline First & $\mathrm{k}_{1}$ & 0.0500 & 0.0850 & 0.0710 & 0.0740 & 0.1130 & 0.0940 & 0.1310 & 0.1050 & 0.0440 & 0.0090 & 0.0590 & 0.0480 \\
\hline Order & $\mathrm{R}^{2}$ & 99.0000 & 91.4000 & 96.3 .000 & 97.4000 & 91.8000 & 97.0000 & 88.3000 & 93.3000 & 94.6000 & 97.3 .000 & 99.7000 & 98.5000 \\
\hline Pseudo & qe & 12.9800 & 12.3400 & 11.24 .00 & 11.6300 & 14.7050 & 15.1500 & 15.3800 & 15.8730 & 4.8500 & 4.9000 & 4.8500 & 5.9500 \\
\hline Second & $\mathrm{k}_{2}$ & 0.0019 & 0.0039 & 0.0084 & 0.0086 & 0.0027 & 0.0031 & 0.0034 & 0.0036 & 0.0094 & 0.0115 & 0.0115 & 0.0107 \\
\hline Order & $\mathrm{R}^{2}$ & 95.8000 & 98.4000 & 99.8000 & 99.8000 & 87.9000 & 99.0000 & 95.1000 & 98.6000 & 97.2000 & 99.9000 & 99.8000 & 99.0000 \\
\hline Diffusion & $\mathrm{k}_{\mathrm{d}}$ & 1.1210 & 1.0940 & 0.8510 & 0.865 & 2.0210 & 2.0860 & 1.9220 & 1.5920 & 0.4720 & 0.4690 & 0.4380 & 0.5550 \\
\hline Model & $\mathrm{R}^{2}$ & 96.3000 & 98.0000 & 97.5000 & 96.000 & 98.9000 & 98.9000 & 98.4000 & 99.7000 & 94.3000 & 98.2000 & 98.4000 & 97.1000 \\
\hline
\end{tabular}

Table 3. Kinetic parameters for adsorption of MB on MPS at different temperatures

\begin{tabular}{|c|c|c|c|c|c|c|c|c|c|}
\hline \multirow[b]{2}{*}{$\mathrm{T}(\mathrm{K})$} & \multicolumn{3}{|c|}{ Unfunctionalized MPS } & \multicolumn{3}{|c|}{ Methyl functionalized MPS } & \multicolumn{3}{|c|}{ Phenyl functionalized MPS } \\
\hline & $\begin{array}{l}\Delta \mathrm{G}^{\circ} \\
(\mathrm{kJ} / \mathrm{mol})\end{array}$ & $\begin{array}{l}\Delta \mathrm{H}^{\circ} \\
(\mathrm{kJ} / \mathrm{mol})\end{array}$ & $\begin{array}{l}\Delta \mathrm{S}^{\circ} \\
(\mathrm{J} / \mathrm{mo})\end{array}$ & $\begin{array}{l}\Delta \mathrm{G}^{\circ} \\
(\mathrm{kJ} / \mathrm{mol})\end{array}$ & $\begin{array}{l}\Delta \mathrm{H}^{\circ} \\
(\mathrm{kJ} / \mathrm{mol})\end{array}$ & $\begin{array}{l}\Delta \mathrm{S}^{\circ} \\
(\mathrm{J} / \mathrm{mol})\end{array}$ & $\begin{array}{l}\Delta \mathrm{G}^{\circ} \\
(\mathrm{kJ} / \mathrm{mol})\end{array}$ & $\begin{array}{l}\Delta \mathrm{H}^{\circ} \\
(\mathrm{kJ} / \mathrm{mol})\end{array}$ & $\begin{array}{l}\Delta \mathrm{S}^{\circ} \\
(\mathrm{J} / \mathrm{mol})\end{array}$ \\
\hline 288 & -12.562 & 55.13 & 235.8 & -13.12 & 37.12 & 175.8 & -10.722 & 16.719 & 99.2 \\
\hline 298 & -15.469 & & & -15.86 & & & -10.727 & & \\
\hline 308 & -17.654 & & & -17.16 & & & -12.793 & & \\
\hline 318 & -19.651 & & & -18.48 & & & -13.197 & & \\
\hline
\end{tabular}

Table 4. Thermodynamic quantities obtained from the Langmuir model MPS/methylene blue adsorption system

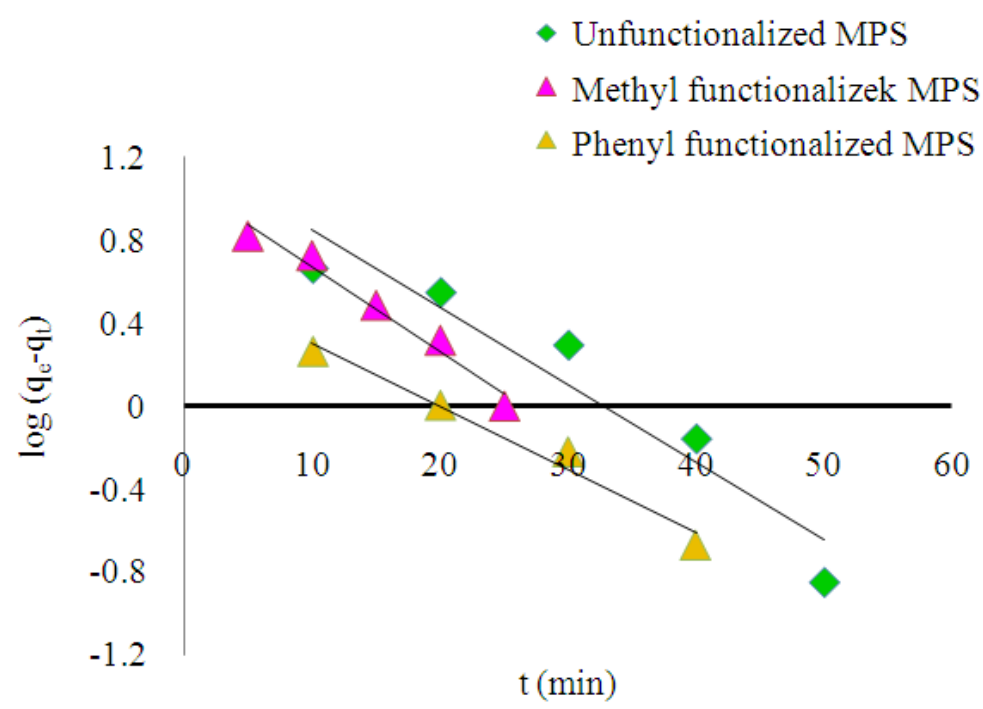

(a) 


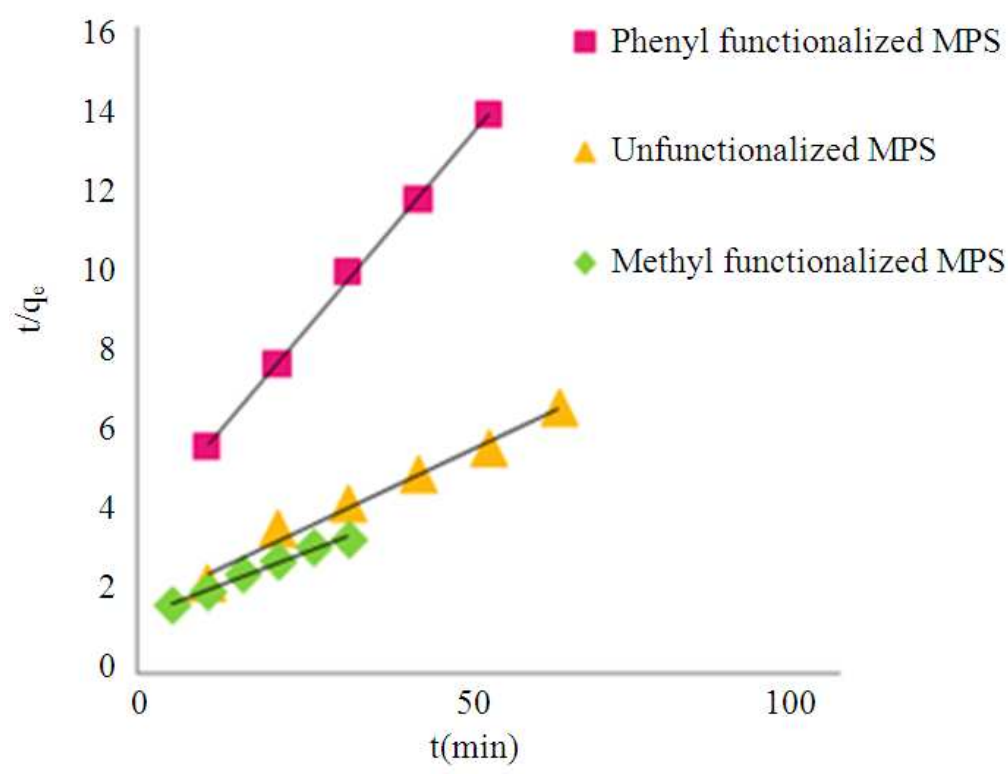

(b)

• Methyl functionalized MPS

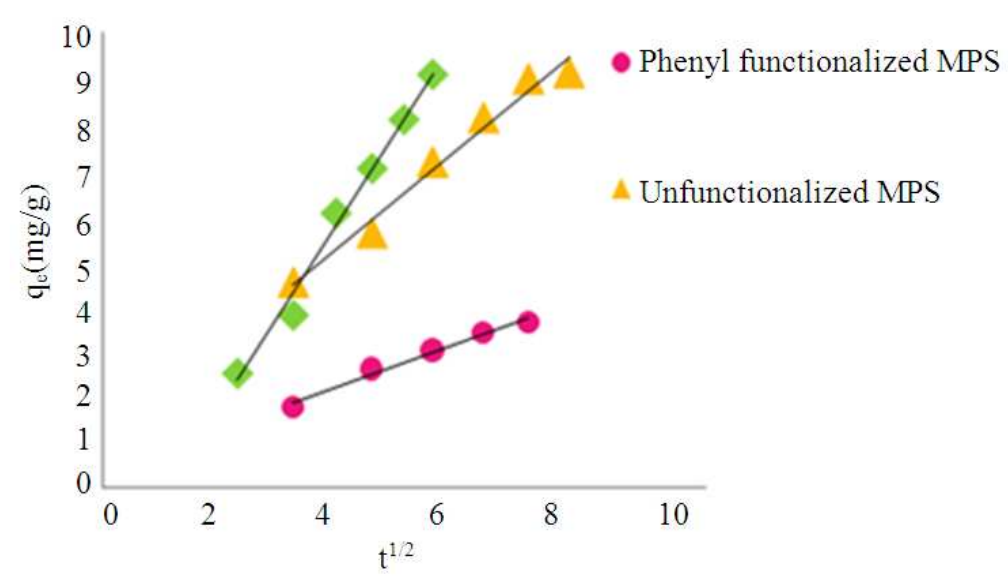

(c)

Fig. 7. Kinetic plots for adsorption of MB on MPS at 298 K; (a) pseudo-first-order, (b) pseudo-second order and (c) diffusion model

\section{DISCUSSION}

\subsection{Textural Analysis}

The amount of $\mathrm{N}_{2}$ adsorbed of the initial part for phenyl functionalized sample isotherm is very low, indicating that the micropores may be ignored in this sample. The uptake of the intial part for the other two silica samples are high, suggesting that there are micropores in these samples.
As can be seen from Table 1, the specific surface area, total pore volume expressed per 1 gram of the silica and $\mathrm{BJH}$ average pore size decrease when the silica functionalized with phenyl group but increased when functionalized with methyl group. However, it should be noted that quite significant changes in the structural properties related to the blockage of pores can be observed for the modification of mesoporous with large group. 


\subsection{Adsorption Study}

It is known that dyes adsorption mechanisms depend on the adsorbent structure, dye's molecular structure, and temperature, especially if there are significant differences in their specific surface areas and porosity. There are three consecutive mass transport steps associated with the adsorption of solute from solution by porous adsorbent, i.e., the adsorb ate migrated through the solution to the external surface of the adsorbent particles by molecular diffusion, solute movement from the particles surface into internal sites by pore diffusion and the adsorb ate is adsorbed onto active sites at the interior of the adsorbent particles.

\subsubsection{Effect of Adsorbent Dose}

Adsorbent dose is representing of important parameter due to its strong effect on the capacity of an adsorbent at given initial concentration of adsorbate. The results show increasing of adsorotion efficiency with increasing the dosage of different types of MPS which can be explained by increasing surface area of adsorption take place (Al-Khatib et al., 2012).

However, the amount of $\mathrm{MB}$ adsorbed reached maximum value by using $50 \mathrm{mg} / 50 \mathrm{~mL}$ for all MPS samples and reach constant after that which can be attibuted to the attainment of equilibrium between adsorbate and adsorbent under the operating conditions. The adsorption process reached a saturation point after which no further MB adsorption took place.

\subsubsection{Adsorption Isotherm}

The adsorption equilibrium isotherm is important for describing how the adsorbate molecules distribute between the liquid and the solid phases when the adsorption process reaches an equilibrium state.

It can be seen from Table 2 that the correlation coefficient $\left(\mathrm{R}^{2}\right)$ values of Langmuir model are higher than those of Freundlich model for all samples. This indicates that the isotherms of the three sample are best fitted by Langmiur equation and this model may be more appropriate for description of adsorption process. The values of the Frendulich isotherm parameter $\mathrm{n}$ are more than one at all temperatures, indicates high adsorption intensity.

\subsubsection{Adsorption Kinetics}

The chemical kinetics describes reaction pathways, along times to reach the equilibrium whereas chemical equilibrium gives no information about pathways and reaction rates.

From the Table 3, the second-order kinetics seems to be good for modeling the kinetics of the whole adsorption process and the regression coefficients are greater than the first-order kinetic model. From the results, it is observed that the equilibrium adsorption from the pseudo-second order model is close to the experimental data suggesting the better application of the second-order kinetics.

The results of intraparticle model shows deviations of lines from which indicate that the intraparticle diffusion step and other steps such as surface adsorption step are operating during the adsorption of $\mathrm{MB}$ on the silica prepared (Tan et al., 2009).

\subsubsection{Thermodynamics Analysis}

The negative value of free energy change indicated the spontaneous nature of sorption. This suggests high preference of methylene blue for MPS (ALzaydien, 2009). As seen from Table 4, the positive value of adsorption enthalpy in the case of unfunctionalized, methyl and phenyl functionalized MPS shows that the adsorption process is endothermic. The positive values of $\Delta S^{\circ}$ indicate the decrease in the order of the system.

\section{CONCLUSION}

- Unfunctionalized and methyl and phenyl functionalized MPS were prepared by sol-gel process and characterized by FT-IR, TG and $\mathrm{N}_{2}$ adsorptiondesorption analysis. The analysis of $\mathrm{N}_{2}$ sorption shows that the maximum surface area of $646.9 \mathrm{~m}^{2} / \mathrm{g}$ is obtained for methylfunxtionalized MPS

- $\quad \mathrm{MB}$ adsorption tests in aqueous solution show that these material exhibit significant difference in adsorption behavior. The adsorption capacities for samples prepared are 13.51, 14.49 and $9.61 \mathrm{mg} / \mathrm{g}$ for Unfunctionalized and methyl and phenyl functionalized MPS

- The adsorption isotherm are well fitted with Langmuir model, also the fitting of Frendlich model shows that they are also favorable adsorption

- The adsorption kinetics of MB on the three sample prepared are well described by a pseudo-second order kinetic model and the intraparticle diffusion model suggests that the adsorption process proceeds by surface sorption and intraparticle diffusion 


\section{REFERENCES}

Al-Khatib, L., F. Fraige, M. Al-Hwaiti and O. AlKhashman, 2012. Adsorption from aqueous solution onto natural and acid activated bentonite. Am. J. Environ. Sci., 8: 510-522. DOI: 10.3844/ajessp.2012.510.522.

ALzaydien, A.S., 2009. Adsorption of methylene from aqueous solution onto a low-cost natural jordanian tripoli. Am. J. Environ. Sci., 5: 197-208. DOI: 10.3844/ajessp. 2009. 197-208.

Anbia, M. and S.A. Hariri, 2010. Removal of methylene blue from aqueous solution using nanoporous SBA3. Desalination, 261: 61-66. DOI: 10.1016/j.desal.2010.05.030

Barrett, E.P., L.G. Joyner and P.P. Halenda, 1951. The determination of pore volume and area distributions in porous substances. I. Computations from nitrogen isotherms. J. Am. Chem. Soc., 73: 373-380. DOI: 10.1021/ja01145a126

Branton, P.J., P.G. Hall and K.S.W. Sing, 1993. Pysisorption of nitrogen and oxygen by MCM-41, a model mesoporous adsorbent. J. Chem. Soc. Chem. Commun., $\quad 16$ : 1257-1258. DOI: 10.1039/C39930001257

Brunauer, P., P.H. Emmett and E. Teller, 1938. Adsorption of gases in multimolecular layers. J. Am. Chem. Soc., 60: 309-319. DOI: 10.1021/ja01269a023

Chung, D.W., J.P. Kim, D. Kim and J. Lim, 2006. Synthesis of multifunctional epoxy monomers and their potential application in the production of holographic photopolymers. J. Industrial Engineer. Chem. 12: 783-789.

Corma, A., P. Atinzar, H. Garcia and J.Y. ChaneChing, 2004. The instant-direct-templating synthesis of phenyl-functionalized HOM-type mesoporous silica materials. Nat. Mater. 3: 394402. DOI: $10.1038 /$ nmat 1129

Desplantier-Giscard, D.T.D., C. Danumah and S. Kaliaguine, 2001. Mesostructured fatty acid-tethered silicas: Sustaining the order by co-templating with bulky precursors. Appl. Catal A., 22: 299-357.

Freundlich, H.M.F., 1906. Over the adsorption in solution. J. Phys. Chem., 57: 385-385.

Johanson, E.M., 2010. Controlling the pore size and morphology of mesoporous silica. Linkoping University.
Karaca, S., A. Gurses, M. Acıkyıldız and M. Ejder, 2008. Adsorption of cationic dye from aqueous solutions by activated carbon Korucu. Microporous Mesoporous Mater., 115: 376-382. DOI: 10.1016/j.micromeso.2008.02.008

Lagergren, S.Y., 1898. Zur theorie der sogenannten adsorption geloster stoffe. 1st Edn., Kungliga Svenska Vetenskapsakademiens, Handlingar, pp: 39.

Langmuir, I., 1918. The adsorption of gases on plane surfaces of glass, mica and platinum. J. Am. Chem. Soc., 40: 1361-1403. DOI: 10.1021/ja02242a004

Li, X.D. and Q.Z. Zhai, 2011. Characterization of methylated nanoscale MCM-41 material. J. Iran. Chem. Socity, 8: 1-8. DOI: 10.1007/BF03254276

Liu, Y.R., 2009. One-pot synthesis of ordered mesoporous carbon silica nanocomposites templated by mixed amphiphilic block copolymers. J. Mater. Sci., 44: 3600-3607. DOI: 10.1007/s10853-0093487-7

McKay, G. and Y.S. Ho, 1999. Pseudo-second order model for sorption processes. Process Biochem., 34: 451-465. DOI: 10.1016/S0032-9592(98)00112-5

Meynen, V., P. Cool and E.F. Vansant, 2009. Verified syntheses of mesoporous materials. Micropor Mesopor Mater., 125: 170-223. DOI: 10.1016/j.micromeso.2009.03.046

Monnier, A., F. Schüth, Q. Huo, D. Kumar and D. Margolese et al., 1993. Cooperative Formation of Inorganic-organic interfaces in the synthesis of silicate mesostructures. Science, 261: 1299-303. DOI: 10.1126/science.261.5126.1299

Norhasyimi, R., Z.A. Ahmed and M. AbdulRahman, 2010. A Review: Mesoporous Santa Barbara Amorphous-15, Types, Synthesis and Applications towards Biorefinery production. Am. J. Appl.Sci. 7:1579-2010. DOI: 10.3844/ajassp.2010.1579.1586

Onal, Y., 2006. Kinetics of adsorption of dyes from aqueous solution using activated carbon prepared from waste apricot. J. Hazard. Mater., 137: 17191728. DOI: 10.1016/j.jhazmat.2006.05.036

Rami, A.O. and E.R. Houssam, 2009. Synthesis and characterization by FTIR spectroscopy of silica aerogels prepared using several $\mathrm{Si}(\mathrm{OR}) 4$ and RSi(OR)3 precursors. J. Molecul. Structure, 919: 140-145. DOI: 10.1016/j.molstruc.2008.08.025

Rouquerol, J., D. Avnir, C.W. Fairbridge, D.H. Everett and J.H. Haynes et al., 1994. Physical and biophysical chemistry division commission on colloid and surface chemistry including catalysis. Pure Appl. Chem., 66: 1739-1758. DOI: 10.1351/pac199466081739 
Ryouya, H., T. Yasuhiro and M. Ogawa, 2012. The syntheses of thin layers of organosilica by the cocondensation of tetraethoxysilane and phenyltriethoxysilane in the presence of cationic surfactant. J. Mater. Sci., 47: 2195-2200. DOI: 10.1007/s10853-011-6023-5

Sing, K.S.W., D.H. Everett, R.A.W. Haul, L. Moscou and R.A. Pierotti et al., 1985. Reporting physisorption data for gas/solid systems with special reference to the determination of surface area and porosity. Pure Appl. Chem., 57: 603-619. DOI: 10.1351/pac198557040603

Soni, M., A.K. Sharma, J.K. Srivastava and J.S. Yadav, 2012. Adsorptive removal of methylene blue dye from an aqueous solution using water hyacinth root powder as a low cost adsorbent. Int. J. Chemical Sci. Applic., 3: 338-345.
Tan, I. A., A.L. Ahmed and B.H. Hameed, 2009. Adsorption isotherms, kinetics, thermodynamics and desorption studies of 2,4,6 trichlorophenol on oil plam empty fruit bunch-baced activated carbon. J. Hazard Mater., 164: 473-482. DOI: 10.1016/j.jhazmat.2008.08.025

Wang, S. and H. Li, 2006. Structure directed reversible adsorption of organic dye on mesoporous silica in aqueous solution. Microporous Mesoporous Mater., 97: 21-26. DOI: 10.1016/j.micromeso.2006.08.005

Weber, W.L. and J.C. Morris, 1963. Kinetics of adsorption on carbon from solution. J. Sanitary Engineer. Divis., ASCE, 89: 31-39.

Yu, M.A., M. Kanezashi and T. Toshinori, 2010. Preparation of organic/inorganic hybrid silica using methyltriethoxysilane and tetraethoxysilane as coprecursors. J. Sol-Gel Sci. Technol., 53: 93-99. DOI: 10.1007/s10971-009-2061-8 